\title{
Food biotechnology: food industry, nutrition and public health
}

\author{
BY MILLY RYAN-HARSHMAN \\ FEAST Enterprises, Food and Technology Consulting, 947 Oshawa Boulevard North, Oshawa, Ontario \\ LIG 5V7, Canada
}

One memory from my childhood is that of my mother frying potatoes in shortening. I can still hear the sound of the fries in the paper bag as she shook them to remove some of the grease. And, she was heavy-handed with the salt too. Today, my family eats potatoes fried in a 'favourable'-fatty acid-profile oil. People have changed, foods have changed, and more changes will come.

To meet the objectives of the present symposium, the present review will cover 'pro' and 'con' positions regarding the public health impact of food biotechnology.

Food biotechnology is the use of living organisms, or parts of living organisms, to create new, or improved, food products. Applications of biotechnology that involve recombinant DNA techniques (genetic engineering), the most controversial food technology today, generate questions about economics, ethics and the environment never before asked. The ability of scientists to transfer genetic material from any living organism to another alarms those individuals who are uncomfortable with the role of science and technology in society.

Despite support from organizations such as the American Medical Association (1991), the American Dietetic Association (1993) and Canadian Dietetic Association (1995), the World Health Organization (WHO) and the Food and Agriculture Organization (FAO; FAO/WHO, 1996), opposition to food biotechnology exists from environmental groups, most notably Greenpeace International (1996), and other national and local groups. Although the key issues being debated are about ethics, the environment and economics, the arguments presented generally include a discussion of the impact of food biotechnology on public health. In this context, public health extends beyond food safety to food security. Food security is defined as 'a condition in which all people at all times can acquire safe, nutritionally adequate and personally acceptable foods that are accessible in a manner that maintains human dignity' (Canadian Dietetic Association, 1991). Challenges inherent in achieving food security include: producing abundant food while maintaining a healthy environment; assuring the safety and quality of the food supply; guaranteeing the ability to acquire food; encouraging consumers to choose foods wisely for optimal health (Campbell, 1991).

In the present paper, crop protection, crop improvements, animal technologies and food safety, including diagnostic tools, will be explored for their potential effects on nutrition and public health. Public opinion surveys will be examined in light of consumers' concern for nutritious, safe food and a safe, clean environment.

\section{AGRICULTURAL CHEMICALS AND PUBLIC HEALTH}

Evidence of agricultural chemical contamination of water has been demonstrated in many communities by water sampling of both ground water and surface water. What is not known is the actual impact of such contamination on public health. For example, the use of fertilizers in food production contributes to the average 5-7 mg nitrate/ 1 in American well water. Methaemoglobinaemia, or 'blue baby' syndrome, the only health threat linked to 
nitrates in water, occurs at much higher levels (at least $100 \mathrm{mg} / 1$ ). Other chemicals detected in water include herbicides such as atrazine, a maize herbicide, (US Environmental Protection Agency, 1992). Although epidemiological studies have demonstrated no more than an insignificant risk to human health from pesticide contamination, the perceived threat is sufficient to cause public outcry.

Ames \& Gold (1995) note that $99.99 \%$ of the pesticides in the diet are naturallyoccurring plant pesticides; twenty-nine of the fifty-seven natural pesticides are rodent carcinogens. Only $0.01 \%$ of the pesticides in the human diet are synthetic chemicals; reducing the level of synthetic chemicals will not reduce cancer rates because cancer is largely caused by cigarette smoking, poor diet, and in some countries, infectious disease. In fact, Ames \& Gold (1995) argue that reducing synthetic pesticides will increase the costs of fruits and vegetables and reduce consumption.

Critical thinking leads most scientists to eliminate the concept of organic farming as a solution to synthetic chemical use because the land requirements necessary to counteract yield losses will force the conversion of wildlands to agriculturally-productive land. However, organic farming can play a minor role in the reduction of synthetic chemicals in the environment, and there is a small market for these more expensive foods. A logical conclusion to be drawn, then, is to find new ways to reduce use of synthetic fertilizers and pesticides in farming. Biotechnology already provides food producers with an alternative to some pesticides and, although not yet realized, the potential for reduced use of fertilizers exists.

The ability to use broad-spectrum herbicides on rapeseed and soyabeans is one of the first applications of biotechnology to food production. The benefits of this technology as stated by company spokespersons (Monsanto Canada Inc., Mississauga, Ontario, Canada, personal communication) is that crops can be protected by an environmentally-benign broad-spectrum herbicide with a wide application window. Herbicide-tolerant crops may also enhance the farmers' abilities to practice no-till farming, an agriculturally-sustainable method of preventing soil erosion. Yet, Greenpeace International (1996) uses data on agricultural workers and glyphosate poisonings and low level detection of glyphosate residues in food to convince society of the dangers of herbicide-tolerant crops to public health. What Greenpeace International (1996) fails to mention is that the use of more harmful pesticides decreases and overall pesticide use declines. The issue, then, is not whether a good scientist can refute the arguments of Greenpeace International (1996), but whether the general public can; Greenpeace International distributes its information via the Internet as well as through traditional routes.

The transfer of genes from Bacillus thuringiensis $(\mathrm{Bt})$ into plants like potato, maize and cotton allows growers to eliminate or reduce their use of pesticides against key insect pests. Despite studies demonstrating that the action of Bt depends on specific binding sites in target insects (Hofmann et al. 1988; Slaney et al. 1992), critics have suggested that human subjects with low gastric acidity will be harmed by the intact Bt protein.

Most of the claims that food biotechnology will increase human health risks can be dealt with effectively, but determining whether biotechnology is compatible with sustainable agriculture is more complex. Cohen (1996) facetiously describes sustainability movements as the 'bigger pie', using science and technology in both developed and developing countries; 'fewer forks', implementing population control methods, particularly in developing countries; 'better manners', re-engineering society through socialism.

Sustainable agriculture is defined as the production of food to meet the needs of today without hindering the ability of future generations to meet their needs. Proponents of sustainable agriculture include organic farmers, public health professionals, agricultural 
researchers and senior managers at multi-national corporations. Each group presents different perspectives on agricultural sustainability and within groups divergent points of view exist (Duvick \& Crouch, 1992). Whatever the final contents of a sustainable agriculture policy, the necessity of such a policy has been well-documented (Hudson Institute, 1991; Hart, 1997).

\section{CROP IMPROVEMENTS AND CHRONIC DISEASE}

Crop improvements that can alter fatty acids or modify starch content have the potential to reduce the risk of chronic disease. Unlike the indirect benefits of 'environmentally friendly' farming on public health, crop improvements can directly affect consumers. Yet controversy exists regarding these technologies, even though they are years away from the market place. The central question posed by many is 'Do we change the food supply or do we change the consumer to meet health needs?' One involves evolution within the food industry, the other involves a revolution in nutrition education.

Food fortification to improve the nutritional quality of diets was first practised during the mid-1900s. By the mid-2000s, there will be a strong likelihood that foods will be 'fortified' in the field. Fruits and vegetables could mature in the field with higher levels of phytochemicals, or the ability to produce certain phytochemicals could be transferred to other plant foods. The potential of foods to provide health benefits is known as functional foods research, which is somewhat of a misnomer because all foods are functional. The term nutraceuticals may be more appropriate, even though it tends to medicalize the food supply. Biotechnology, specifically genetic engineering, will assist the food industry in capturing the highest market potential of functional foods. At the same time, nutrition education efforts will have to change to keep up with improvements in the food supply. For example, will the nutrition educator's message about French fries need to be revised when starch-modified potatoes are widely used in food processing?

To identify the true complexity of this issue, several approaches must be examined, that of the nutrition educator, the farmer, and the food processors and distributors. One of the most prominent nutrition educators today, Joan Dye Gussow, is also one of biotechnology's greatest critics. In a time when consumer awareness of the link between diet and health is increasing, Gussow \& Akabas (1993) state that nutrition educators should redouble their efforts to change the food choices of consumers, preferably with an influx of dollars from the private sector to fund nutrition education projects. Such a position is not without merit. Were it not for the unwillingness of the consumer to change their eating habits and the inability of the agricultural sector to quickly meet new demands, this would be the ideal way to improve public health.

O'Brien (1995) examined the implications for agriculture if a Mediterranean-type diet were adopted by the majority of Americans, most of whom only consume half the recommended intakes of fruits and vegetables. He drew the following conclusions about fruit and vegetable production, which is the area of productivity that would see the most dramatic changes. The fruit and vegetable sector could double its output, but not without significant trade-offs. Acreage expansion would be small in absolute terms, but the availability of land suitable for such purposes would be limited. The use of fertilizers and agrichemicals in the fruit and vegetables sector is much greater than that for other crops. Finally, competition for water would reach critical levels if production output in this sector doubled to meet a changed consumer demand. Changes in the cereals, dairy and meat sectors would also be necessary, although some changes have already occurred. Improved genetics have led to leaner meat and greater milk production. Further changes will 
probably involve the use of recombinant porcine somatotropin and recombinant bovine somatotropin (rBST). In addition food processors have begun offering a variety of leaner, processed meats and lower-fat milks.

Smith (1993) observed that, traditionally, the food industry has not been technology driven. Yet, four recent forces will move the food industry towards greater use of technology to create marketable products. These four forces are: changing demographics and consumer lifestyles; changing profile of the food industry; the growing fitness food market; public policy issues affecting lifestyles. For example, the US National Cholesterol Education Program has as its mandate to lower cholesterol and fat intakes among its target group: society. This federal government programme will encourage the food industry to persist in the development of lower-fat and fat-free foods.

Given the previously mentioned difficulties with changing food production to meet food choices, food redesign is an attractive alternative. Complementary activities of nutrition research and nutrition education in both the public and private sector will be necessary. Most particularly, public education efforts will need to be supported with private sector dollars. Working in cooperation, nutrition educators and the food industry can maximize the opportunities for consumers to move towards more healthy eating.

The potential to change fatty acid composition among oilseed crops using biotechnology exists, although a greater allocation of resources to this type of genetic engineering research will be necessary (Somerville, 1993). The food applications of oils produced through gene modifications are many. The priority for today's consumer is to consume oils with reduced saturated fat, but it is the saturated fat which provides stability in processing. If, through gene modifications, oils can be produced that are low in saturated fats, but do not degrade (oxidize) quickly and have good frying performance, then, the food-service industry will more readily purchase 'healthy' oils (Erickson \& Frey, 1994). In Canada, rapeseed is a likely crop with which to experiment because its market has grown rapidly, and its growth can continue if access to other oil markets can be achieved through biotechnology.

The question that must be asked is 'Will consumers accept foods that are produced or processed using biotechnology?'. Consumer surveys indicate, in general, that the answer to that question depends on the type of genetic engineering applied to the food.

\section{GENETIC ENGINEERING AND FOOD CONSUMPTION PATTERNS}

Now, when nutrition educators are encouraging consumers to adopt a healthier diet, society must examine issues that may negatively affect food consumption patterns. Such was the case with rBST. Nutrition educators were genuinely concerned that consumers would reduce their intake of milk and milk products because they were afraid of the use of genesplicing techniques in food production. Some surveys predicted that milk consumption would drop by about $25 \%$ or more following the introduction of milk from rBST-treated cows (Optima Consultants in Applied Social Research, 1994).

Over 1500 scientific articles have been published about rBST, including some excellent review articles (Bauman, 1992; Burton et al. 1994). The safety and benefits of rBST have been specifically addressed by researchers, federal regulators, and key health agencies (Daughaday \& Barbano, 1990; Juskevich \& Guyer, 1990; National Institutes of Health, 1991; Etherton et al. 1993; United States Federal Government, 1994); yet, there have been a few notable articles taking exception to the safety and benefits of rBST. Kronfeld (1994) stated that the extra-label use of antibiotics to treat rBST-related mastitis could have an impact on public health because of detection weaknesses within the milk 
monitoring system. Mepham (1992) concluded that the evidence regarding the human safety of insulin-like growth factor- 1 in milk from rBST-treated cows was not sufficient to unequivocally support milk safety. He also stated that adverse changes in the nutrient composition of milk or the altered food composition patterns of a public suspicious of new technology would cause detrimental changes in the $\mathrm{Ca}$ and protein nutriture of human subjects.

In the USA, where milk from rBST-treated cows has been in the market place since early 1994, milk consumption patterns have not changed. In 1994, total fluid sales of milk increased by $0.67 \%$, and in 1995 , no change was observed in total fluid sales (United States Department of Agriculture, 1996). Were consumers to reject milk from rBST-treated cows, the expectation would have been that milk sales dramatically declined at first introduction of rBST when consumer awareness was highest.

In the Optima Consultants in Applied Social Research (1994) survey, $34 \%$ of the respondents said it was unlikely they would continue to buy milk if rBST were used in Canada. Of those responding, $13 \%$ negatively switched their answer when they were informed that milk was pooled in Canada. Another $13 \%$ of those responding negatively were unsure whether they would buy milk on being informed that treated and untreated milk would be pooled (Optima Consultants in Applied Social Research, 1994). Opinion surveys are subject to three key biases that make drawing conclusions difficult. These are: (1) if an explanation of the issue is required, it will be uncertain how strongly previously uninformed consumers hold their views; (2) whether stated intentions will translate into action is unknown. Surveys conducted before the actual occurrence of the event may not be valid; (3) surveys that request individuals to identify their concerns may sensitize them to a potential safety hazard, thereby overestimating public anxiety. The only valid data available on milk consumption are, therefore, the data from the United States Department of Agriculture (1996).

Consumers' food consumption patterns may be altered only in certain circumstances. Food products developed through biotechnology will vary in their levels of acceptability. Crop applications, such as food crops that are protected from insect damage, were acceptable to nearly two-thirds of respondents in two separate surveys. In a Food Marketing Institute survey, approximately $80 \%$ of respondents would accept the use of biotechnology if the goal was to reduce the fat content of foods (Hoban, 1996). One might conclude from these surveys that if consumers can recognize a direct (nutritional) or indirect (environmental) benefit of biotechnology, their approval of its use rises.

Engaging the public in the discussion of new agricultural technologies will have an impact on public perception, and perhaps public health. The Lay Panel of the UK National Consensus Conference on Plant Biotechnology (1994) and the Christian Farmers Federation of Ontario (1995) workshop are examples of public participation. The Institute of Food Technologists, Office of Scientific Public Affairs (1988) observed that the food production and distribution system is complex and not well understood, which leads to distrust, and that it is understandable, but not attainable, to want zero risk in foods. Public discussion of alternatives may change consumers' concept of risk and increase their acceptance of technology. Consumers want to have a role in risk and benefit analysis and decision-making.

\section{BIOTECHNOLOGY, FOOD SAFETY AND PUBLIC HEALTH}

When the issue of food safety arises, most people can remember a food item that has been recalled because of a safety issue. When the same people are asked about the regulations 
governing the food supply, a blank look probably crosses their faces! Thus, a discussion of when the regulatory system protects public health, and how that system protects public health is necessary regarding food biotechnology. I will focus on the Canadian regulatory system for my own convenience, but the FAO statement on the safety of foods from biotechnology (FAO/WHO, 1996) will be presented to broaden the discussion globally. Also, an important part of food safety includes the diagnostic tools needed by food safety inspectors. In this area, biotechnology plays a significant role, and warrants attention.

The Canadian regulatory system is complex and comprehensive; yet, this system is continuously revisited and revised to meet changes in the food supply. The most significant change to date with respect to this system has been the introduction of guidelines within both Agriculture and Agri-Food Canada and Health Canada to deal with foods that are the result of biotechnology.

Agriculture and Agri-Food Canada regulates agricultural products of biotechnology, including veterinary vaccines and biologically-active compounds, genetically-modified plants, and biofertilizers and feed. The Seeds Act, the Feeds Act, the Fertilizer Act and the Health of Animals Act have recently been amended regarding the regulations for environmental safety assessments. For example, the environmental assessment for a plant with a novel trait must contain information about the potential of the novel plant to become a weed of agriculture or to invade natural habitats, the potential of gene flow to wild relatives whose hybrid offspring may become more weedy or invasive, the potential impact of the novel plant or its gene products on non-target species, and the potential impact on biodiversity. Confined field trials must be conducted before approval for unconfined or commercial release, which may also be subject to certain conditions. Once the plant with a novel trait enters commercial production, any new information about the novel plant's impact on the environment must be reported by law. At that time, new conditions or different conditions could be imposed or authorization to release could be denied or cancelled (Agriculture and Agri-Food Canada, 1993, 1997).

The primary objection that critics have of the regulatory system is that the confined trials only address agronomic characteristics. Critics call for the need to examine the ecological risks by determining invasiveness in uncontrolled, uncultivated situations, and to conduct experiments in a variety of locations globally to ensure global ecological safety (Kareiva \& Parker, 1994). To meet the demand for such experimentation would be costly, probably preventing biotechnology from being used as a tool to ensure greater food security, an important principle of public health practice.

The environmental safety of transgenic plants is one contentious issue between proponents and opponents of biotechnology, but the risks to human health are debated frequently. In Canada, the determination of the safety of a novel food rests with Health Canada. Guidelines for the Safety Assessment of Novel Foods (Health Canada, 1994a,b) have been prepared, but adoption is dependent on a final consultative period. The guidelines use the principle of substantial equivalence; labelling will be required only in the event of a significant change in nutritional composition or risk of allergenicity. The issue of allergenicity is hotly debated. Under the novel-food guidelines, considerations include the source of the transferred genetic material, its molecular weight, its sequence homology to known allergens, its prevalence in foods, its heat and processing stability, and its reaction to $\mathrm{pH}$ and digestive proteases. These characteristics allow regulators to predict likelihood of allergenicity.

Risk assessment and risk management are not new to Canadian regulators, but the potential introduction of allergens into the food supply via genetic engineering has required that regulators explain risk assessment and risk management to a sceptical public. Those 
who are the most qualified to communicate about risk are not the most trusted, and any event is subject to at least two interpretations. The transfer of a Brazil (Bertholletica excelsa)-nut allergen to soyabeans provides an excellent case study. Some have declared that the situation proves the effectiveness of safety regulations; others have stated that the situation demonstrates the weaknesses of safety regulations.

Nordlee et al. (1996) identified that the transfer of a specific gene from the Brazil-nut, a known allergen, into soyabeans produced an allergic response in subjects allergic to Brazil-nuts. The researchers concluded that transfer of allergens between foods by genetic engineering does indeed occur, and that allergenicity should be assessed under human experimental conditions when possible. The authors cautioned that such tests are only valuable when the transferred genetic material is known to be from an allergenic source. It is the authors' final statement that prompted Marion Nestle, a well-known US public health expert to respond in an editorial. Nestle (1996) called for an expansion of basic and clinical research on food allergies and stronger federal regulations for transgenic foods that include premarketing notification and labelling.

The FAO/WHO Expert Consultation on Biotechnology and Food Safety (FAO/WHO, 1996) issued four specific recommendations on allergenicity. These are:

1. the transfer of genes from commonly allergenic foods should be discouraged unless it can be documented that the gene transferred does not code for an allergen;

2. foods found to contain an allergen transferred from the organism which provided the DNA should not be considered for marketing approval unless such products can be clearly identified in the market-place and this identity will not be lost through distribution and processing. Further, that labelling approaches may not be practical in these situations, and that particular problems exist for consumers who cannot read, or who may not be provided with labels;

3. involved organizations should consider the appropriateness of, and/or actions to take, in respect to foods containing new protein(s) that are determined to have the characteristics of an allergen, even though no patient population is known to exist which has an allergy to this gene product;

4. the identification of food allergens and the characteristics of these allergens that define their immunogenicity be encouraged.

The overall message regarding the food industry, biotechnology and public health with respect to allergenicity appears to be one of move forward with caution. Particular attention must be paid to the characteristics of a novel trait that may elicit allergic responses; the industry must be committed to thorough safety assessments and collection of information in appropriate databases. Governments worldwide must strive to ensure global safety by developing and implementing guidelines that both promote industrial innovation and protect public health.

\section{FOOD SAFETY DIAGNOSTICS AND PUBLIC HEALTH}

Food and water contaminants such as Salmonella, Listeria, Escherichia coli $\mathrm{O} 157: \mathrm{H} 7$ and Cryptosporidium are major human health problems. Canada has one of the safest food supplies in the world. However, two million cases of food-borne illnesses are reported annually in Canada. Many of these food-borne illnesses can be eliminated by proper foodhandling education. This education is taking place at the restaurant and food services level in cooperation with public health departments. Consumers are being made more aware of 
the problem through media campaigns, public education efforts, and even commercials. Even with education efforts, food-borne illnesses will occur.

Biotechnology will allow for the development of diagnostic tests for food safety. Such diagnostic devices will allow for online detection of pathogens during food processing; this type of detection would enhance the Hazard Analysis of Critical Control Points analyses (Griffiths, 1996) currently employed. As few as three to five Salmonella cells in $25 \mathrm{~g}$ food can be detected in naturally-contaminated chicken carcasses, beef and milk samples (Degrandts, 1996). The tools of biotechnology can ensure that food purchased by restaurants or institutions will be safer. Safer food, in combination with safer food handling practices, will reduce the number of food-borne illnesses, and keep medical costs and productivity losses down.

\section{NUTRITION EDUCATION, LABELLING AND PUBLIC HEALTH}

Food safety education and nutrition education will provide significant benefits to consumers. However, even the nature of what constitutes education is subject to differing viewpoints.

In public health nutrition, the food label has been used as an educational tool. The label has been effectively used to teach people how to determine the fat content of the foods they choose to eat with some success. Some have suggested that the use of the food label as an educational tool be expanded by the addition of information to the label. At least one Canadian province has developed enabling legislation for organic foods that could be reinterpreted to allow for the development of food labels that denote the social justice, ethical, or environmental implications of food purchases (BC Food Choice and Disclosure Act; Province of British Columbia, 1991).

Any decisions about labelling should be based on the scientific basis for labelling, that of health and safety. Labelling provides information about the contents of the packaged product that allows consumers to make appropriate food choices and protects manufacturers from unfair competition. The ingredient list will provide the allergic individual with information about the food product, such as whether the product contains peanuts, but labelling is not the appropriate method for handling perceived food safety concerns. Foods with a valid safety concern are not marketed for human consumption (Congress of the United States, 1991).

The Council for Agricultural Science and Technology (1994) reiterates that labelling requirements should not depend on the process by which food was produced, but on the safety and nutritional characteristics of food. Indeed, identification of processes on the label would require that food crops be separated in the field and throughout the processing and distribution streams. However, labelling guidelines for Canada and other countries do allow for voluntary positive or negative labelling for niche markets, i.e. markets that are willing to pay higher prices for speciality foods.

\section{CONCLUSION}

What then, should our goals for nutrition and public health be? Our goals should be to continue creating products that meet a variety of needs and preferences, to continue educating the public about food choices that help to maintain health, and to continue developing effective working relationships between nutrition researchers, nutrition practitioners, and the food industry. The dissemination of information through symposiums such as this one, workshops, consensus conferences, free help lines (1-800 numbers), 
newsletters, electronic communication and, most importantly, well-funded nutrition education projects will keep the public abreast of changes in the food industry that affect nutrition and public health. The responsibility for safe, nutritious food is a shared responsibility, shared among regulatory authorities, the food industry, researchers, health professionals, growers, processors and food distributors.

\section{REFERENCES}

Agriculture and Agri-Food Canada (1993). Biotechnology in Agriculture General Information. Ottawa: Biotechnology Strategies and Coordination Office.

Agriculture and Agri-Food Canada (1997). Regulations for Environmental Safety Assessments. Ottawa: Biotechnology Strategies and Coordination Office.

Ames, B. N. \& Gold, L. S. (1995). The causes and prevention of cancer: The role of environment. In The True State of the Planet, pp. 141-176 [R. Bailey, editor]. New York: The Free Press.

American Dietetic Association (1993). Position of the American Dietetic Association: Biotechnology and the future of food. Journal of the American Dietetic Association 93, 189-192.

American Medical Association (1991). Biotechnology and the American agricultural industry. Journal of the American Medical Association 265, 1429-1436.

Bauman, D. E. (1992). Bovine somatotropin: Review of an emerging animal technology. Journal of Dairy Science 75, 3432-3450.

Burton, J. L., McBride, B. W., Block, E., Glim, D. R. \& Kennelly, J. J. (1994). A review of bovine growth hormone. Canadian Journal of Animal Science 74, 167-201.

Campbell, C. C. (1991). Food security from the consumer's perspective: An agenda for the 1990s. Journal of the Canadian Dietetic Association 52, 83-88.

Canadian Dietetic Association (1991). Hunger and food security in Canada: Official position of the Canadian Dietetic Association. Journal of the Canadian Dietetic Association 52, 139.

Canadian Dietetic Association (1995). The Canadian Dietetic Association Biotechnology Committee opinion paper on biotechnology and food. Journal of the Canadian Dietetic Association 56, 63-67.

Christian Farmers Federation of Ontario (1995). Biotechnology and Creation Stewardship: Report on Christian Farmers Federation of Ontario Workshop. Woodbridge, ON: Touchstone Public Affairs and Communications Consulting.

Cohen, J. E. (1996). Maximum occupancy. American Demographics 18, 44-51.

Congress of the United States (1991). U.S. Dairy Industry at a Crossroad: Biotechnology and Policy Choices. Washington, DC: Office of Technology Assessment.

Council For Agricultural Science and Technology (1994). Labeling of Food-plant Biotechnology Products: Issue Paper. Ames, Iowa: Council for Agricultural Science and Technology.

Daughaday, W. H. \& Barbano, D.M. (1990). Bovine somatotropin supplementation of dairy cows: Is the milk safe? Journal of the American Medical Association 264, 1003-1005.

Degrandts, S. (1996). Biotech food safety diagnostics: Big benefits, big business. Agri-food Research in Ontario 19, 51 .

Duvick, D. \& Crouch, M. (1992). Is biotechnology compatible with sustainable agriculture? Ag Bioethics Forum. Ames. Iowa: Iowa State University.

Erickson, M. D. \& Frey, N. (1994). Property-enhanced oils in food applications. Food Technology 48, 63-68.

Etherton, T. D., Kris-Etherton, P. M. \& Mills, E. W. (1993). Recombinant bovine and porcine somatotropin: Safety and benefits of these biotechnologies. Journal of the American Dietetic Association 93, 177-180.

Food and Agriculture Organization/World Health Organization (1996). FAO/WHO Expert Consultation on Biotechnology and Food Safety. Rome: FAO.

Greenpeace International (1996). Not Ready for Roundup: A Critique of Monsanto's Risk Evaluation. Amsterdam: Greenpeace International.

Griffiths, M. W. (1996). Toward rapid on-line detection of pathogens for food processing. Agri-Food Research in Ontario 19, 53.

Gussow, J. D. \& Akabas, S. (1993). Are we really fixing up the food supply? Journal of the American Dietetic Association 93, 1300-1304.

Hart, S. L. (1997). Beyond greening: Strategies for a sustainable world. Harvard Business Review 75, 66-76.

Health Canada (1994a) Guidelines for the Safety Assessment of Novel Foods, vol 1. Ottawa: Food Directorate, Health Protection Branch.

Health Canada (1994b). Guidelines for Safety Assessment of Novel Foods, vol. 2. Ottawa: Food Directorate, Health Protection Branch.

Hoban, T. J. (1996). Trends in consumer acceptance and awareness of biotechnology. Journal of Food Distribution Research 27, 1-10. 
Hofmann, C., Vanderbruggen, H., Hofte, H., Van Rie, J., Jansens, S. \& Van Mellaert, H. (1988). Specificity of Bacillus thuringiensis delta-endotoxins is correlated with the presence of high-affinity binding sites in the brush border membrane of target insect midguts. Proceedings of the National Academy of Sciences USA 85, $7844-7848$.

Hudson Institute (1991). In Global Food Progress 1991: A Report from Hudson Institute's Center for Global Food Issues [D. T. Avery, editor]. Indianapolis, Indiana: Hudson Institute.

Institute of Food Technologists, Office of Scientific Public Affairs (1988). The risk/benefit concept as applied to food: A scientific status summary by the Institute of Food Technologists' Expert Panel on Food Safety \& Nutrition. Food Technology 42, 119-126.

Juskevich, J. C. \& Guyer, C. G. (1990). Bovine growth hormone: Human food safety evaluation. Science 24, 875-884.

Kareiva, P. \& Parker, I. (1994). Environmental Risk of Genetically Engineered Organisms and Key Regulatory Issues. Amsterdam: Greenpeace International.

Kronfeld, D. S. (1994). Health management of dairy herds treated with bovine somatotropin. Journal of the American Veterinary Medical Association 204, 116-130.

Mepham, T. B. (1992). Public health implications of bovine somatotropin use in dairying: discussion paper. Journal of the Royal Society of Medicine 85, 736-739.

Nestle, M. (1996). Allergies to transgenic foods - questions of policy (Editorial). New England Journal of Medicine 334, 726-727.

National Institutes of Health (1991). NIH technology assessment conference statement on bovine somatotropin. Journal of the American Medical Association 265, 1423-1425.

Nordlee, J. A., Taylor, S. L., Townsend, J. A., Thomas, L. A. \& Bush, R. K. (1996). Identification of a Brazil-nut allergen in transgenic soybeans. New England Journal of Medicine 334, 688-692.

O'Brien, P. (1995). Dietary shifts and implications for US agriculture. American Journal of Clinical Nutrition 61, Suppl., 1390S-1396S.

Optima Consultants in Applied Social Research (1994). Understanding the Consumer Interest in the New Biotechnology Industry: Study Findings. Ottawa: Industry Canada.

Province of British Columbia (1991). Food Choice and Disclosure Act. Victoria: Queen's Printer for British Columbia.

Slaney, A. C., Robbins, H. L. \& English, L. (1992). Mode of action of Bacillus thuringiensis toxin Cryll1A: An analysis of toxicity in Leptinotarsa decemlineata (Say) and Diabrotica undecimpunctata howardi barber. Insect Biochemistry and Molecular Biology 22, 9-18.

Smith, R. E. (1993). Food demands of the emerging consumer: the role of modern food technology in meeting that challenge. American Jourral of Clinical Nutrition 58, Suppl., 307S-312S.

Somerville, C. R. (1993). Future prospects for genetic modification of the composition of edible oils from higher plants. American Joumal of Clinical Nutrition 58, Suppl., 270S-275S.

The Lay Panel of the UK National Consensus Conference on Plant Biotechnology (1994). Final Report. London: Science Museum.

United States Department of Agriculture (1996). US Dairy Product Highlights 1991 Through 1995. Washington DC: USDA, Industry Affairs.

United States Federal Government (1994). Use of Bovine Somatotropin (BST) in the United States: Its Potential Effects. Washington, DC: Executive Branch.

US Environmental Protection Agency (1992). Another Look: National Survey of Pesticides in Drinking Water Wells, Phase 2 Report, EPA 570-9-91-020. Washington, DC: Government Printing Office. 